\title{
Brief report: the association between recreational versus therapeutic marijuana use on hazardous alcohol consumption and alcohol-associated behavioral consequences among adults living with HIV in Florida
}

Zachary L. Mannes ${ }^{1}$, Erin G. Ferguson ${ }^{1}$, Larry E. Burrell ${ }^{2}$, Robert L. Cook ${ }^{3}$ and Nicole Ennis ${ }^{1 *}$

\begin{abstract}
Background: Though marijuana use has previously been associated with risky alcohol use, studies often do not delineate between the effect of recreational versus therapeutic marijuana use, particularly among people living with HIV (PLWH). In this study, we examined the association between recreational versus therapeutic marijuana use to manage HIV symptoms (i.e., improve appetite/gain weight, induce sleep, relieve nausea/vomiting, relieve pain, relieve anxiety/depression/stress) on hazardous alcohol consumption and associated behavioral consequences among PLWH.
\end{abstract}

Methods: PLWH (N=703) recruited from community health centers in Florida completed questionnaires assessing sociodemographics, marijuana use motives (i.e., recreational versus therapeutic), alcohol use, and alcohol-associated behavioral consequences. Hazardous alcohol use was defined as consuming 5 or more drinks on one occasion at least monthly or > 14 drinks per week for men, or 4 drinks on one occasion at least monthly or $>7$ drinks per week for women over the past 12 months, while alcohol-associated behavioral consequences were assessed via the Short Inventory of Problems Revised (SIP-R). A one-way analysis of covariance (ANCOVA) assessed differences in average number of alcohol-associated behavioral consequences between recreational and therapeutic marijuana users, and non-users, while multivariate logistic regression analysis evaluated the association between reason for marijuana use and hazardous alcohol consumption.

Results: There was a significant effect of marijuana use group on SIP-R score after controlling for covariates $[F(2,579)=3.04, p=0.048]$, with post hoc analysis demonstrated significantly fewer alcohol-associated behavioral consequences among therapeutic marijuana users (1.27) compared to recreational users (3.35; $p=0.042$ ). Compared to non-users, therapeutic marijuana users demonstrated significantly lower odds of hazardous drinking $(A O R=0.42,95 \% \mathrm{Cl}=0.18-0.96, p=0.041)$, while recreational marijuana users were $64 \%$ more likely to report hazardous drinking $(A O R=1.64,95 \% \mathrm{Cl}=1.08-2.50, p=0.019)$.

\footnotetext{
* Correspondence: nennis@phhp.ufl.edu

'Department of Clinical and Health Psychology, College of Public Health and Health Professions, University of Florida, P.O. Box 100165, 1225 Center Drive, Room 3146, Gainesville, FL 32610-0165, USA

Full list of author information is available at the end of the article
}

(c) The Author(s). 2018 Open Access This article is distributed under the terms of the Creative Commons Attribution 4.0 International License (http://creativecommons.org/licenses/by/4.0/), which permits unrestricted use, distribution, and reproduction in any medium, provided you give appropriate credit to the original author(s) and the source, provide a link to the Creative Commons license, and indicate if changes were made. The Creative Commons Public Domain Dedication waiver (http://creativecommons.org/publicdomain/zero/1.0/) applies to the data made available in this article, unless otherwise stated. 


\begin{abstract}
(Continued from previous page)
Conclusions: Findings from this study add to the literature by demonstrating how differing marijuana use motives are associated with hazardous alcohol consumption among PLWH. Given our findings showing greater risk of hazardous alcohol consumption among recreational marijuana users and lower risk among therapeutic marijuana users, results from this study may help inform interventions to reduce harmful alcohol consumption and associated adverse consequences among PLWH.
\end{abstract}

Keywords: HIV/AIDS, Hazardous alcohol use, Marijuana use

\section{Background}

Hazardous alcohol use is defined by having 5 or more drinks on one occasion (at least monthly) or $>14$ drinks per week for men, and 4 drinks on one occasion (at least monthly) or $>7$ drinks per week in the past 12 months for women [1-3]. Previous studies have found that hazardous alcohol use is more prevalent among people living with HIV (PLWH) compared to the general population and is associated with missed clinic appointments, decreased retention in care, suboptimal antiretroviral adherence, and increased morbidity and mortality [4-8].

Though factors associated with hazardous alcohol consumption include depression, illicit drug use, and marijuana use, hazardous alcohol use and alcohol-associated behavioral consequences may differ based on whether PLWH use marijuana recreationally or for therapeutic purposes to manage HIV-associated medical symptoms [9]. In the USA, up to $56 \%$ of PLWH report current marijuana use [10]. While many PLWH report recreational motives for use, approximately $60 \%$ report use to manage HIV-associated symptoms such as pain, nausea, lack of appetite, insomnia, and depression [10-12].

The literature examining the effect of medical versus recreational marijuana use on alcohol consumption behaviors remains inconclusive [13]. Though medical marijuana is often considered that prescribed by a physician, marijuana is one of the most common types of complementary and alternative medicines used by adults living with HIV in Florida, with many PLWH reporting self-management of medical symptoms as the primary reason for use [14]. Given that motives of alcohol use among PLWH include managing HIV-associated medical symptoms such as pain, stress, and depression, treatments (i.e., marijuana use) to alleviate similar symptoms may influence alcohol consumption patterns in this population, as previous studies have shown that alcohol drinkers reduce use when marijuana is an accessible alternative to relieve medical symptoms $[15,16]$. To this point, results from a recent study demonstrated a significantly lower prevalence of hazardous alcohol use among therapeutic marijuana users (i.e., persons using marijuana to self-manage specific symptoms or health conditions; $24.0 \%)$ compared to recreational marijuana users (49.1\%) and non-users (32.4\%) [9]. Building upon these results, in this study, we examined the effect of recreational versus therapeutic marijuana use on hazardous alcohol consumption and alcohol-associated behavioral consequences among PLWH in Florida. We hypothesized that compared to non-users, therapeutic marijuana users would demonstrate significantly lower odds of hazardous drinking while recreational marijuana users would be more likely to report hazardous drinking. We further hypothesized that therapeutic marijuana users would report significantly fewer alcohol-associated behavioral consequences compared to recreational marijuana users and non-users.

\section{Methods}

\section{Participants and procedures}

Study methods have been previously detailed [17]. Briefly, the sample $(N=703)$ included participants recruited from 2014 to 2017 for the Florida Cohort Study, an investigation examining determinants of health outcomes of PLWH in Florida. The Florida Cohort Study utilizes a convenience-sampling method of data collection across multiple county health departments and community setting clinics throughout Florida (Gainesville, Ft. Lauderdale, Lake City, Miami, Orlando, Sanford, and Tampa). All PLWH 18 and older at the selected recruitment settings were eligible to participate. After providing written informed consent, participants completed questionnaires assessing sociodemographics, depressive symptoms, and substance use. Participants received $\$ 25.00$ after study completion. The Institutional Review Boards of the University of Florida, Florida International University, and Florida Department of Health approved this study.

\section{Measures \\ Marijuana use}

Participants were asked if they used any marijuana in the past 3 months. Since data collection for this study occurred prior to the 2017 legalization of physicianprescribed medical marijuana in Florida, recreational and therapeutic marijuana users were defined based on self-reported motives for use, in line with prior research in collaboration with the CDC [18]. Recreational 
marijuana users endorsed use to get high or stoned, increase libido/improve sexual performance, or fit into social situations. Therapeutic marijuana users reported use to improve appetite/gain weight, induce sleep, relieve nausea/vomiting, relieve pain, and relieve anxiety/ depression/stress. Participants endorsing both recreational and therapeutic marijuana use were classified as recreational users, whereas therapeutic users were those reporting therapeutic use only.

\section{Hazardous alcohol use}

Participants reported the average frequency and quantity of consumption of standard alcoholic beverages in the past year. Average weekly consumption was calculated by multiplying the average daily quantity by the average frequency per week. Participants also reported on how often they drank 4+ standard drinks (for women) or 5+ standard drinks (for men) on one occasion, as well as the largest number of drinks they consumed within a 24-h period. Participants were classified as either hazardous or non-hazardous users based on their report of meeting hazardous drinking criteria (i.e., 5 or more drinks on one occasion at least monthly or $>14$ drinks per week for men, or 4 drinks on one occasion at least monthly or $>7$ drinks per week for women) [1-3].

\section{Alcohol-associated behavioral consequences}

The Short Inventory of Problems Revised (SIP-R) is a valid and reliable questionnaire for measuring alcoholassociated negative consequences related to physical or monetary harm, relationship discord, and impulsive decision-making over the past 30 days. Participant SIP-R scores ranged from 0 to 15 , and the scores were averaged and compared among recreational and therapeutic marijuana users and non-users [19].

\section{Durable viral suppression}

HIV viral suppression was defined as all viral load tests suppressed $(\leq 200$ copies $/ \mathrm{ml})$ in the past year, based on information available from statewide HIV surveillance data.

\section{Other substance use}

Participants were dichotomized as to whether they reported use of any illicit drugs other than marijuana (i.e., ecstasy, crack/cocaine, nonprescription opioid use, and injection drugs) in the past year.

\section{Depressive symptoms}

The Patient Health Questionnaire (PHQ-8), a reliable and valid instrument for PLWH, was used to define current depressive symptoms (i.e., a score of $\geq 10$ ), consistent with prior research $[20,21]$.

\section{Sociodemographic factors}

Age, race, sex, education, sexual identity, years since diagnosis, and homelessness were assessed. For the purpose of our analyses, participants were categorized into four age groups: $18-34,35-44,45-54$, and $\geq 55$. Race/ ethnicity was categorized into Hispanic, White, Black, and Others. Sex was based on participant's assigned sex at birth (i.e., male or female). Level of education was classified into three groups: less than high school, high school, and more than high school. Sexual identity was categorized as heterosexual, homosexual, or bisexual. Years since diagnosis was a continuous variable assessing number of years since HIV diagnosis. Homelessness was defined as living in a homeless shelter, emergency shelter, car, street, or abandoned building in the last year.

\section{Statistical analyses}

Analyses were conducted in SPSS version 24 [22]. Descriptive statistics were used to analyze sociodemographic factors and the prevalence of depressive symptoms, illicit drug use, motives of marijuana use, and hazardous drinking. Sex, age, race, education, sexual identity, homelessness, depressive symptoms, other drug use, years since diagnosis, and durable viral suppression were included as covariates in multivariate analysis, as prior research suggests associations with risky alcohol use among PLWH $[5,7,8]$. A one-way analysis of covariance (ANCOVA) with adjustment for the aforementioned covariates assessed differences in average number of alcohol-associated behavioral consequences between recreational users, therapeutic marijuana users, and non-users. Following observation of a significant main effect, pairwise comparisons between the three groups were made using the Bonferroni correction. The level of significance was set at $p<0.05$. Multivariate logistic regression assessed the association between therapeutic versus recreational marijuana use and hazardous drinking. Adjusted odds ratios with 95\% confidence limits were presented with non-users as the referent group.

\section{Results}

\section{Sample characteristics}

The sample $(N=703)$ had a mean age of 47 years $(\mathrm{SD}=11.27)$. The $\mathrm{racial} / \mathrm{ethnic}$ breakdown was $53.7 \%$ Black, 22.4\% White, 20.4\% Hispanic, and 3.5\% Other. Most participants $(68.7 \%)$ were males, and $62.2 \%$ reported completing high school or less. The majority (81.0\%) reported being unmarried. Mean years since HIV diagnosis was $11.52(\mathrm{SD}=7.61)$. Approximately $36 \%$ of PLWH reported hazardous alcohol consumption (Table 1). 
Table 1 Demographics, substance use, mental health, and health status $(N=703)$

\begin{tabular}{|c|c|c|}
\hline Variable & Category & $\begin{array}{l}\text { Total } \\
(N=703)\end{array}$ \\
\hline \multicolumn{3}{|l|}{ Demographics } \\
\hline \multirow[t]{4}{*}{ Age } & $18-34$ & $112(16.2)$ \\
\hline & $35-44$ & $124(17.9)$ \\
\hline & $45-54$ & $279(40.4)$ \\
\hline & $\geq 55$ & $176(25.5)$ \\
\hline \multirow[t]{2}{*}{ Sex } & Male & $475(68.7)$ \\
\hline & Female & 216 (31.3) \\
\hline \multirow[t]{4}{*}{ Race } & Hispanic & $141(20.4)$ \\
\hline & Not Hispanic, White & $155(22.4)$ \\
\hline & Not Hispanic, Black & $371(53.7)$ \\
\hline & Not Hispanic, Other & $24(3.5)$ \\
\hline \multirow[t]{3}{*}{ Education } & $<$ High school & $220(31.9)$ \\
\hline & $\begin{array}{l}\text { High school diploma } \\
\text { or equivalent }\end{array}$ & $208(30.2)$ \\
\hline & $>$ High school & $261(37.9)$ \\
\hline \multirow[t]{3}{*}{ Sexual identity } & Heterosexual & $341(51.2)$ \\
\hline & Homosexual & $260(39.0)$ \\
\hline & Bisexual & $65(9.8)$ \\
\hline \multirow[t]{2}{*}{ Homelessness } & No & $576(84.5)$ \\
\hline & Yes & $106(15.5)$ \\
\hline \multicolumn{3}{|l|}{ Substance use } \\
\hline \multirow[t]{2}{*}{ Marijuana use } & No & $469(66.8)$ \\
\hline & Yes & $234(33.2)$ \\
\hline \multirow[t]{2}{*}{ Other drug use } & No & $416(63.2)$ \\
\hline & Yes & $242(36.8)$ \\
\hline \multirow[t]{2}{*}{ Hazardous drinking } & No & $417(63.9)$ \\
\hline & Yes & $236(36.1)$ \\
\hline \multicolumn{3}{|l|}{ Mental health } \\
\hline \multirow[t]{2}{*}{ Depressive symptoms } & No & $465(68.2)$ \\
\hline & Yes & $216(31.8)$ \\
\hline \multicolumn{3}{|l|}{ Health status } \\
\hline \multirow[t]{2}{*}{ Viral suppression } & No, at least once $>200$ & $263(40.2)$ \\
\hline & Yes, all $\leq 200$ & $390(59.8)$ \\
\hline
\end{tabular}

Note: $N$ may vary slightly according to missing data

\section{Recreational and therapeutic marijuana use}

Marijuana use in the past 3 months was reported by $33.2 \%$ of participants. After categorization, 51 (7.2\%) of all participants were therapeutic users, 183 (26.0\%) were recreational users, and 469 (66.8\%) were nonusers (Fig. 1). Additional information related to participant marijuana use and motives of use have been published elsewhere [9].
The association between marijuana use motive, alcoholassociated consequences, and hazardous drinking Therapeutic marijuana users reported 1.27 alcohol-associated behavioral consequences compared to 3.35 and 2.79 for recreational users and non-users respectively. After controlling for sex, age, race, education, sexual identity, homelessness, depressive symptoms, other drug use, years since diagnosis, and durable viral suppression, there was a significant effect of marijuana use motive on the total number of reported drinking consequences $[F(2,579)=$ 3.04, $p=0.048]$. Bonferroni-corrected post hoc analysis demonstrated a significant difference in SIP-R score between therapeutic marijuana users and recreational users ( $p=0.042)$, while no significant difference was observed between therapeutic users and non-users $(p=0.100)$, nor recreational users and non-users $(p=0.374)$. Compared to non-users, therapeutic marijuana users had significantly lower odds of reporting hazardous drinking $(\mathrm{AOR}=0.42$, $95 \% \mathrm{CI}=0.18-0.96, p=0.041$ ) while recreational marijuana users had approximately a $64 \%$ greater odds of hazardous drinking (AOR $=1.64,95 \% \mathrm{CI}=1.08-2.50, p=0.019)$ after controlling for the aforementioned covariates (see Table 2 and Table 3).

\section{Discussion}

The purpose of this study was to examine the association between marijuana use motives, alcohol-associated behavioral consequences, and hazardous alcohol consumption in a sample of PLWH in Florida. Results demonstrated that therapeutic marijuana users had significantly lower odds of hazardous drinking compared to non-users and also reported significantly fewer alcohol-associated behavioral consequences compared to recreational users. Conversely, recreational users demonstrated greater odds of hazardous drinking compared to non-users. These results suggest that therapeutic marijuana use, rather than recreational marijuana use, may be most useful for minimizing the harmful effects of hazardous alcohol use and associated behavioral consequences. Given these findings, clinicians may be able to evaluate patient risk for hazardous drinking by assessing their rationale for marijuana use.

Complementing findings from the general population, our results indicate that recreational marijuana use confers the greatest risk for hazardous alcohol use and alcohol-associated consequences [23, 24]. This may be a function of the different motives for use. Unlike PLWH reporting therapeutic marijuana use to alleviate health symptoms, recreational users had varying motives, including getting high/stoned, fitting into social situations, and improving sexual performance. In particular, using marijuana to get high/stoned and to fit into social situations may be implicated in recreational users' alcohol consumption, as these social situations could also facilitate alcohol use [25]. Moreover, evidence suggests that 


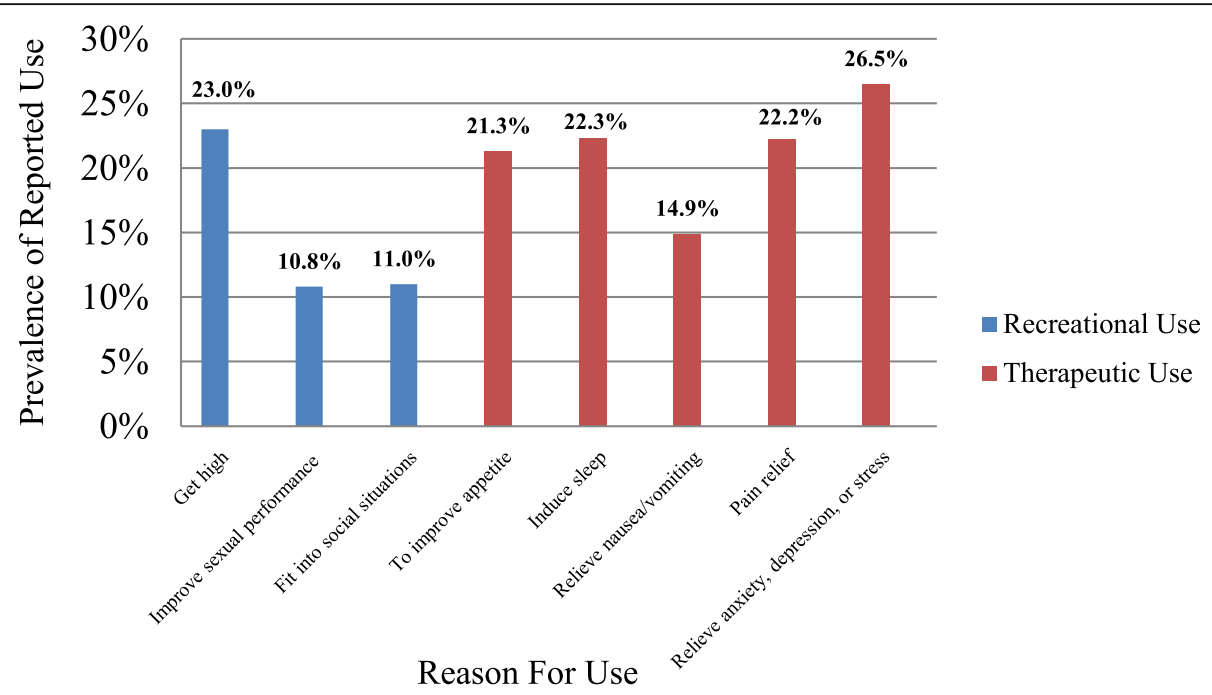

Fig. 1 Prevalence of reported recreational and therapeutic reasons for marijuana use $(n=246)$. Note: Participants could select more than one option

recreational users are more likely to report higher impulsivity, sensation seeking, and disinhibition than nonusers in the general population [26]. Therefore, it is possible that recreational users in this sample used alcohol to seek stimulating experiences associated with potential negative consequences.

Compared to recreational users and non-users, therapeutic marijuana users demonstrated a lower prevalence of hazardous drinking and fewer reported behavioral consequences as a result of their alcohol consumption. Given this, therapeutic users in this study may have substituted their alcohol consumption for marijuana use due to the known deleterious effects of risky alcohol use, and because they perceived marijuana as a more effective means to manage HIV-associated symptomology.
Previous studies have shown that individuals decreased their use of alcohol in locales where medical marijuana was legalized [16, 27, 28]. Lucas and colleagues reported that $41 \%$ of participants used marijuana as a substitute for alcohol, with $60 \%$ noting making this substitution as a result of experiencing fewer side effects, and 52.9\% reporting substitution as a result of more effective medical symptom management with marijuana [16]. Therapeutic users in this study may have engaged in marijuana substitution for similar reasons, resulting in reduced alcohol consumption and associated consequences. Existing literature also suggests that medical marijuana users in the general population are more likely to endorse daily use and have significantly more medical and psychological comorbidities than recreational marijuana users [29]. Therefore,

Table 2 ANCOVA examining the association between recreational and therapeutic marijuana use and alcohol-associated behavioral consequences $(N=703)$

\begin{tabular}{|c|c|c|c|c|c|c|}
\hline Variable & $F$ & $p$ value & $\eta^{2}$ & $M$, non-user & $M$, therapeutic user & $M$, recreational user \\
\hline Marijuana & 3.04 & 0.048 & .011 & 2.79 & 1.27 & 3.35 \\
\hline \multicolumn{7}{|l|}{ Covariates } \\
\hline Sex & 2.70 & 0.311 & .002 & & & \\
\hline Age & 0.31 & 0.860 & .000 & & & \\
\hline Race & 2.54 & 0.111 & .004 & & & \\
\hline Education & 4.33 & 0.038 & .008 & & & \\
\hline Sexual identify & 0.73 & 0.392 & .001 & & & \\
\hline Homelessness & 14.56 & $<0.001$ & .025 & & & \\
\hline Depressive symptoms & 1.96 & 0.162 & .003 & & & \\
\hline Other drug use & 26.05 & $<0.001$ & .044 & & & \\
\hline Years since diagnosis & 1.38 & 0.239 & .002 & & & \\
\hline Durable viral suppression & 0.00 & 0.960 & .000 & & & \\
\hline
\end{tabular}

Note: $M$ mean number of alcohol-associated behavioral consequences. Italicized values indicate significance at $p<0.05$. Adjusted for sex, age, race, education, sexual identity, homelessness, depressive symptoms, other drug use, years since diagnosis, and durable viral suppression 
Table 3 Multivariate logistic regression analysis examining the association between marijuana use motive and hazardous alcohol use $(N=703)$

\begin{tabular}{|c|c|c|}
\hline Variables & $\mathrm{AOR}(\mathrm{Cl})$ & $p$ value \\
\hline \multicolumn{3}{|l|}{ Marijuana use } \\
\hline No marijuana use & Referent & \\
\hline Therapeutic use & $0.42(0.18-0.96)$ & 0.041 \\
\hline Recreational use & $1.64(1.08-2.50)$ & 0.019 \\
\hline \multicolumn{3}{|l|}{ Sex } \\
\hline Male & Referent & \\
\hline Female & $0.92(0.56-1.50)$ & 0.739 \\
\hline \multicolumn{3}{|l|}{ Age } \\
\hline $18-34$ & Referent & \\
\hline $35-44$ & $0.96(0.51-1.81)$ & 0.919 \\
\hline $45-54$ & $0.81(0.44-1.47)$ & 0.491 \\
\hline$\geq 55$ & $0.95(0.47-1.92)$ & 0.906 \\
\hline \multicolumn{3}{|l|}{ Race } \\
\hline Not Hispanic, White & Referent & \\
\hline Not Hispanic, Black & $1.62(0.91-2.88)$ & 0.098 \\
\hline Not Hispanic, Other & $1.15(0.68-1.95)$ & 0.587 \\
\hline Hispanic & $1.32(0.46-3.78)$ & 0.602 \\
\hline \multicolumn{3}{|l|}{ Education } \\
\hline$<$ High school & Referent & \\
\hline High school & $0.83(0.52-1.33)$ & 0.459 \\
\hline > High school & $0.61(0.38-0.99)$ & 0.048 \\
\hline \multicolumn{3}{|l|}{ Sexual identity } \\
\hline Heterosexual & Referent & \\
\hline Homosexual & $1.04(0.63-1.72)$ & 0.866 \\
\hline Bisexual & $0.71(0.35-1.41)$ & 0.332 \\
\hline \multicolumn{3}{|l|}{ Homelessness } \\
\hline No & Referent & \\
\hline Yes & $1.47(0.89-2.43)$ & 0.124 \\
\hline \multicolumn{3}{|l|}{ Depressive symptoms } \\
\hline No & Referent & \\
\hline Yes & $1.29(0.86-1.92)$ & 0.204 \\
\hline \multicolumn{3}{|l|}{ Other drug use } \\
\hline No & Referent & \\
\hline Yes & $2.30(1.57-3.37)$ & $<0.001$ \\
\hline \multicolumn{3}{|l|}{ Years since diagnosis } \\
\hline & $1.01(0.98-1.04)$ & 0.234 \\
\hline \multicolumn{3}{|l|}{ Durable viral suppression } \\
\hline No & Referent & \\
\hline Yes & $0.67(0.45-0.99)$ & 0.047 \\
\hline
\end{tabular}

Note: Italicized values indicate significance at $p<0.05$. Adjusted for sex, age, race, education, sexual identity, homelessness, depressive symptoms, other drug use, years since diagnosis, and durable viral suppression therapeutic users in this sample may have been more likely to use marijuana for treatment purposes and thus limit their use of alcohol due to perceived negative health consequences [30].

Our investigation examining differences in alcohol consumption behaviors yielded novel findings and has some limitations. First, our study utilized a cross-sectional design; thus, we cannot determine the temporality of our findings. Additionally, all participants were PLWH enrolled in care within Florida and thus our findings may not generalize to all PLWH using marijuana. It is also possible that recreational marijuana users in this study may have been engaging in simultaneous substance use (i.e., using marijuana and alcohol at the same time), which was not assessed by the Florida Cohort Study. Despite these limitations, this study found salient differences in alcohol use behaviors between recreational and therapeutic marijuana users. To the author's knowledge, this is the first study examining the association between recreational versus therapeutic marijuana use while controlling for significant covariates in a sample of PLWH.

\section{Conclusions}

Results from this study add to the literature by demonstrating how differing rationales of marijuana use are associated with hazardous alcohol consumption among PLWH. Findings demonstrating greater risk of hazardous alcohol consumption among recreational marijuana users and lower risk among therapeutic marijuana users may help inform interventions to reduce harmful alcohol consumption and prevent adverse consequences among PLWH. Continued research examining the effect of different motives for marijuana use, specifically physician-prescribed marijuana use, on alcohol consumption behaviors among PLWH is important as marijuana legalization proliferates.

\section{Abbreviations}

ANCOVA: One-way analysis of covariance; CDC: Center for Disease Control and Prevention; PLWH: People living with HIV

\section{Acknowledgements}

We appreciate the contributions of the research staff and the participants who were involved in the Florida Cohort study. We also appreciate the contributions of the staff within the Florida Department of Health HIV

Surveillance unit for helping with data on participant viral load.

\section{Funding}

This study was funded by the National Institute on Alcohol Abuse and Alcoholism (NIAAA) [grant number U24AA022002, U24AA022003], National Institute on Drug Abuse (NIDA) [grant number 1K23DA039769-01], and NIDA UF Substance Abuse Training Center [grant number T32DA035167].

\section{Availability of data and materials}

All data affiliated with the Southern HIV and Alcohol Research Consortium can be obtained through the Consortium's website (http://sharc-research.org) upon completion of the organization's concept proposal program as outlined in the Florida Cohort Study IRB submission. 


\section{Authors' contributions}

ZLM conceptualized the research question and drafted the introduction, methods, results, and tables. EGF drafted the discussion and edited the manuscript. LEB edited the manuscript. RLC organized the research study, directed the collaboration between the sites of data collection, and edited the manuscript. NE conceptualized the research question, provided statistical consultation, edited the manuscript, and is the senior author. All authors read and approved the final manuscript.

\section{Ethics approval and consent to participate}

The Institutional Review Boards of the University of Florida, Florida International University, and Florida Department of Health approved this study.

\section{Consent for publication}

Not applicable.

\section{Competing interests}

The authors declare that they have no competing interests.

\section{Publisher's Note}

Springer Nature remains neutral with regard to jurisdictional claims in published maps and institutional affiliations.

\section{Author details}

${ }^{1}$ Department of Clinical and Health Psychology, College of Public Health and Health Professions, University of Florida, P.O. Box 100165, 1225 Center Drive, Room 3146, Gainesville, FL 32610-0165, USA. ²Psychology Service, San Francisco VA Medical Center, 4150 Clement St., San Francisco, CA 94121, USA. ${ }^{3}$ Department of Epidemiology, College of Public Health and Health Professions and College of Medicine, University of Florida, P.O. Box 100231, 2004 Mowry Road, Gainesville, FL 32610, USA.

Received: 6 August 2018 Accepted: 12 November 2018 Published online: 07 December 2018

\section{References}

1. Reid MC, Fiellin DA, O'connor PG. Hazardous and harmful alcohol consumption in primary care. Arch Intern Med. 1999;159(15):1681-9.

2. Force UPST. Screening and behavioral counseling interventions in primary care to reduce alcohol misuse: recommendation statement. Ann Intern Med. 2004;140(7):554.

3. Sharpe JD, Zhou Z, Escobar-Viera CG, Morano JP, Lucero RJ, Ibañez GE, et al. Interest in using mobile technology to help self-manage alcohol use among persons living with the human immunodeficiency virus: a Florida Cohort crosssectional study. Subst Abus. 2018:39(1):77-82.

4. Samet JH, Cheng DM, Libman H, Nunes DP, Alperen JK, Saitz R. Alcohol consumption and HIV disease progression. Journal of acquired immune deficiency syndromes (1999). 2007;46(2):194.

5. Chander G, Lau B, Moore RD. Hazardous alcohol use: a risk factor for nonadherence and lack of suppression in HIV infection. Journal of acquired immune deficiency syndromes (1999). 2006;43(4):411.

6. Justice AC, McGinnis KA, Tate JP, Braithwaite RS, Bryant KJ, Cook RL, et al. Risk of mortality and physiologic injury evident with lower alcohol exposure among HIV infected compared with uninfected men. Drug Alcohol Depend. 2016;161:95-103

7. Crane HM, McCaul ME, Chander G, Hutton H, Nance RM, Delaney JA, et al. Prevalence and factors associated with hazardous alcohol use among persons living with HIV across the US in the current era of antiretroviral treatment. AIDS Behav. 2017;21(7):1914-25.

8. Galvan FH, Bing EG, Fleishman JA, London AS, Caetano R, Burnam MA, et al. The prevalence of alcohol consumption and heavy drinking among people with HIV in the United States: results from the HIV Cost and Services Utilization Study. J Stud Alcohol. 2002;63(2):179-86.

9. Mannes ZL, Ferguson EG, Burrell LE, Cook RL, Ennis N. The association of therapeutic versus recreational marijuana use and antiretroviral adherence among adults living with HIV in Florida. Patient Preference and Adherence. 2018;12:1363-72.

10. Fogarty A, Rawstorne P, Prestage G, Crawford J, Grierson J, Kippax S. Marijuana as therapy for people living with HIV/AIDS: social and health aspects. AIDS Care. 2007;19(2):295-301.
11. D'Souza G, Matson P, Grady CD, Nahvi S, Merenstein D, Weber K, et al. Medicinal and recreational marijuana use among HIV-infected women in the Women's Interagency HIV Cohort (WIHS), 1994-2010. Journal of acquired immune deficiency syndromes (1999). 2012;61(5):618.

12. Woolridge E, Barton S, Samuel J, Osorio J, Dougherty A, Holdcroft A. Cannabis use in HIV for pain and other medical symptoms. J Pain Symptom Manag. 2005:29(4):358-67.

13. Hasin DS. US epidemiology of cannabis use and associated problems. Neuropsychopharmacology. 2018;43(1):195.

14. Kelso-Chichetto NE, Okafor CN, Harman JS, Canidate SS, Cook CL, Cook RL. Complementary and alternative medicine use for HIV management in the state of Florida: medical monitoring project. J Altern Complement Med. 2016;22(11):880-6.

15. Cook RL, Cook CL, Karki M, Weber KM, Thoma KA, Loy CM, et al. Perceived benefits and negative consequences of alcohol consumption in women living with HIV: a qualitative study. BMC Public Health. 2016;16(1):263.

16. Lucas P, Reiman A, Earleywine M, McGowan SK, Oleson M, Coward MP, et al. Cannabis as a substitute for alcohol and other drugs: a dispensary-based survey of substitution effect in Canadian medical cannabis patients. Addict Res Theory. 2013;21(5):435-42.

17. Lucero RJ, Frimpong JA, Fehlberg EA, Bjarnadottir RI, Weaver MT, Cook C, et al. The relationship between individual characteristics and interest in using a mobile phone app for HIV self-management: observational cohort study of people living with HIV. JMIR mHealth and uHealth. 2017;5(7):e100.

18. Schauer GL, King BA, Bunnell RE, Promoff G, McAfee TA. Toking, vaping, and eating for health or fun: marijuana use patterns in adults, US, 2014. Am J Prev Med. 2016;50(1):1-8.

19. Kiluk BD, Dreifuss JA, Weiss RD, Morgenstern J, Carroll KM. The Short Inventory of Problems-Revised (SIP-R): psychometric properties within a large, diverse sample of substance use disorder treatment seekers. Psychol Addict Behav. 2013;27(1):307.

20. Do AN, Rosenberg ES, Sullivan PS, Beer L, Strine TW, Schulden JD, et al. Excess burden of depression among HIV-infected persons receiving medical care in the United States: data from the medical monitoring project and the behavioral risk factor surveillance system. PLoS One. 2014;9(3):e92842.

21. Kroenke K, Strine TW, Spitzer RL, Williams JB, Berry JT, Mokdad AH. The PHQ8 as a measure of current depression in the general population. J Affect Disord. 2009;114(1):163-73.

22. SAS S, Version S. 9.4 [Computer Program]. SAS Institute, Cary. 2003.

23. Goulet-Stock S, Rueda S, Vafaei A, lalomiteanu A, Manthey J, Rehm J, et al. Comparing medical and recreational cannabis users on socio-demographic, substance and medication use, and health and disability characteristics. Eur Addict Res. 2017;23(3):129-35.

24. Roy-Byrne P, Maynard C, Bumgardner K, Krupski A, Dunn C, West II, et al. Are medical marijuana users different from recreational users? The view from primary care. Am J Addict. 2015;24(7):599-606.

25. Buckner JD, Crosby RD, Wonderlich SA, Schmidt NB. Social anxiety and cannabis use: an analysis from ecological momentary assessment. Journal of anxiety disorders. 2012;26(2):297-304.

26. Moreno M, Estevez AF, Zaldivar F, Montes JMG, Gutierrez-Ferre VE, Esteban $L$, et al. Impulsivity differences in recreational cannabis users and binge drinkers in a university population. Drug Alcohol Depend. 2012;124(3):355-62.

27. Reiman A. Cannabis as a substitute for alcohol and other drugs. Harm Reduction Journal. 2009;6(1):35

28. Lau N, Sales P, Averill S, Murphy F, Sato SO, Murphy S. A safer alternative: cannabis substitution as harm reduction. Drug and alcohol review. 2015; 34(6):654-9.

29. Woodruff SI, Shillington AM. Sociodemographic and drug use severity differences between medical marijuana users and non-medical users visiting the emergency department. Am J Addict. 2016;25(5):385-91.

30. Lorenc A, Robinson N. A review of the use of complementary and alternative medicine and HIV: issues for patient care. Aids Patient Care St. 2013;27(9):503-10. 